\title{
Spatiotemporal Assessment of Health Burden and Economic Losses attributable to short-term exposure to Ozone During 2015 - 2018 in China
}

\section{Zihan Zhang}

Sichuan University West China School of Public Health

Minghong Yao

Sichuan University West China School of Public Health

\section{Wenjing Wu}

Sichuan University West China School of Public Health

\section{Xing Zhao}

Sichuan University West China School of Public Health

Juying Zhang ( $\square$ juying109@163.com )

Sichuan University West China School of Public Health and West China Fourth hospital https://orcid.org/0000-0001-8726-142X

\section{Research article}

Keywords: Ozone, Short-term, Health impact, Exposure factors, Economic loss, China

Posted Date: June 9th, 2020

DOl: https://doi.org/10.21203/rs.3.rs-32364/v1

License: (c) (i) This work is licensed under a Creative Commons Attribution 4.0 International License. Read Full License 


\section{Abstract}

Ground-level Ozone $\left(\mathrm{O}_{3}\right)$ pollution is currently the main severe environmental problem in China. Although existing studies have quantified the $\mathrm{O}_{3}$-related health impact and economic loss, few have focused on the acute health effects of short-term exposure to $\mathrm{O}_{3}$ and have been limited to a single temporal and spatial dimension. Based on the $\mathrm{O}_{3}$ concentration obtained from ground monitoring networks in 334 Chinese cities in 2015 - 2018, this study used a two-stage exposure parameter weighted Log-linear exposureresponse function to estimate the cause-specific mortality for short-term exposure to $\mathrm{O}_{3}$. The value of statistical life (VSL) method that were used to calculate the economic loss at the city-level. Our results show that in China, the national all-cause mortality attributed to $\mathrm{O}_{3}$ was $0.18(95 \% \mathrm{Cl}: 0.09-0.36)$ to 0.26 (95\% Cl: 0.13 - 0.45) million across 2015 - 2018. The estimated economic loss caused by $\mathrm{O}_{3}$ was 253.83 (95\% Cl: 128.44 - 590.96) to 397.09 (95\% Cl: 203.54 - 759.27) billion CNY, accounting for $0.34 \%$ to $0.46 \%$ of total reported GDP. Overall, the $\mathrm{O}_{3}$ attributed health and economic burden has begun to decline in China since 2017. However, highly polluted areas still face severe burden, and undeveloped areas suffer from high GDP losses. There are substantial health impacts and economic losses related to short-term $\mathrm{O}_{3}$ exposure in China. The government should pay attention to the emerging Ozone pollution, and continue to strengthen the intervention in traditional priority areas while solving the pollution problem in nonpriority areas.

\section{Full Text}

This preprint is available for download as a PDF.

\section{Figures}



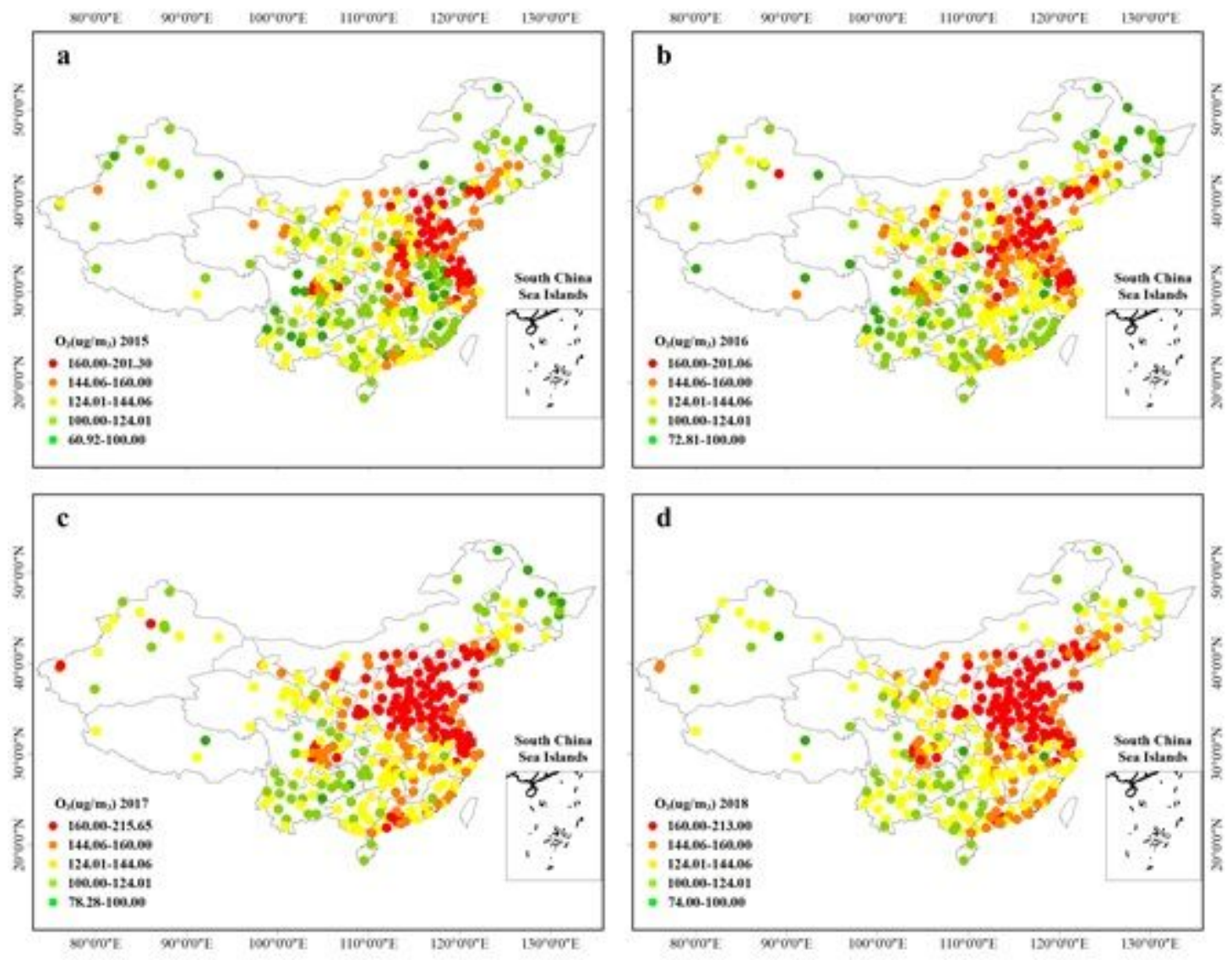

Figure 1

The city-specific annual 90th daily maximum 8-h 03 concentrations in 2015 (a), 2016 (b), 2017 (c) and 2018 (d). 

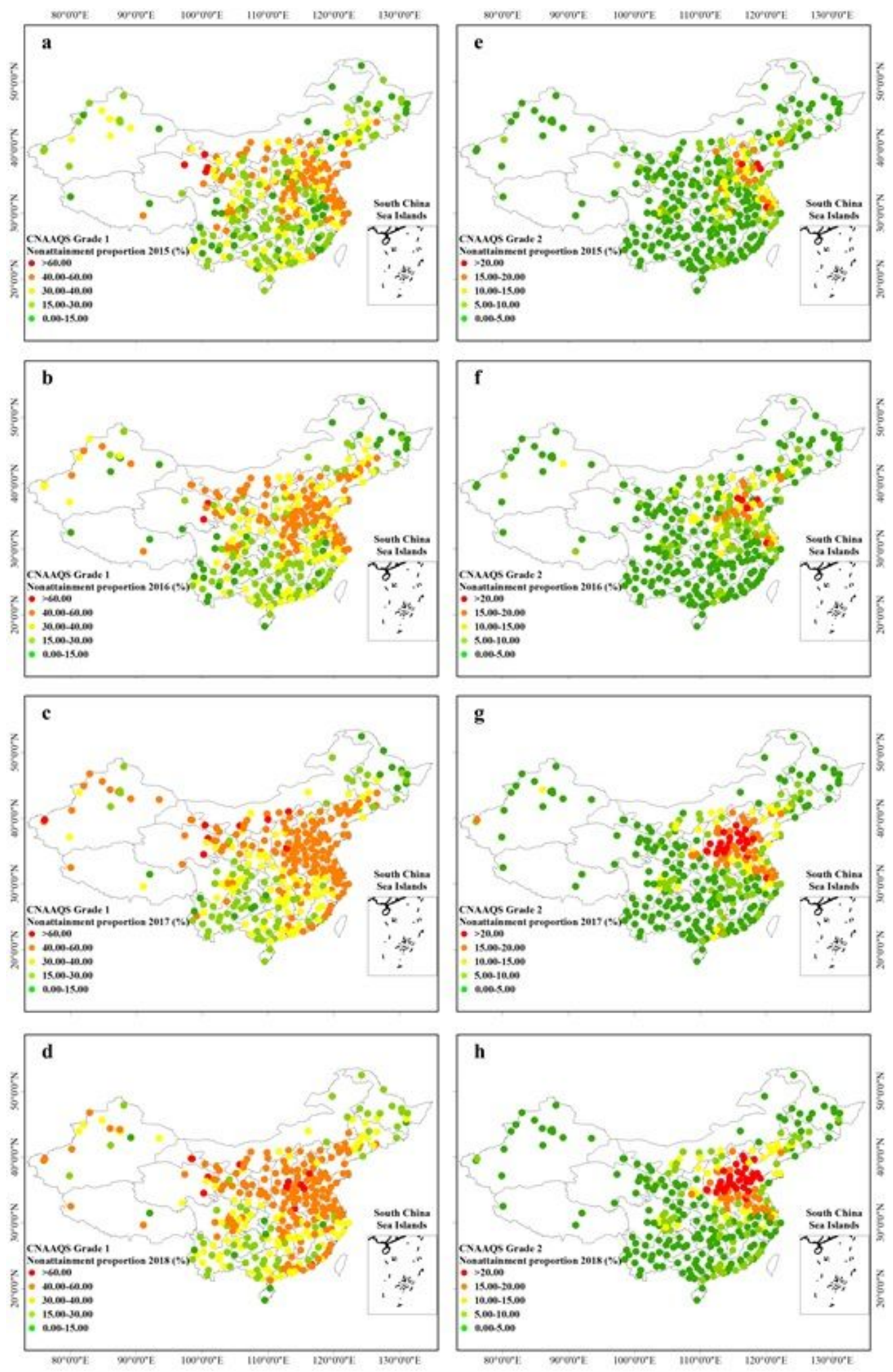

Figure 2

The city-specific nonattainment rate of CNAAQS Grade $\otimes(a-d)$ and Grade $\otimes(e-h)$ during 2015 - 2018 

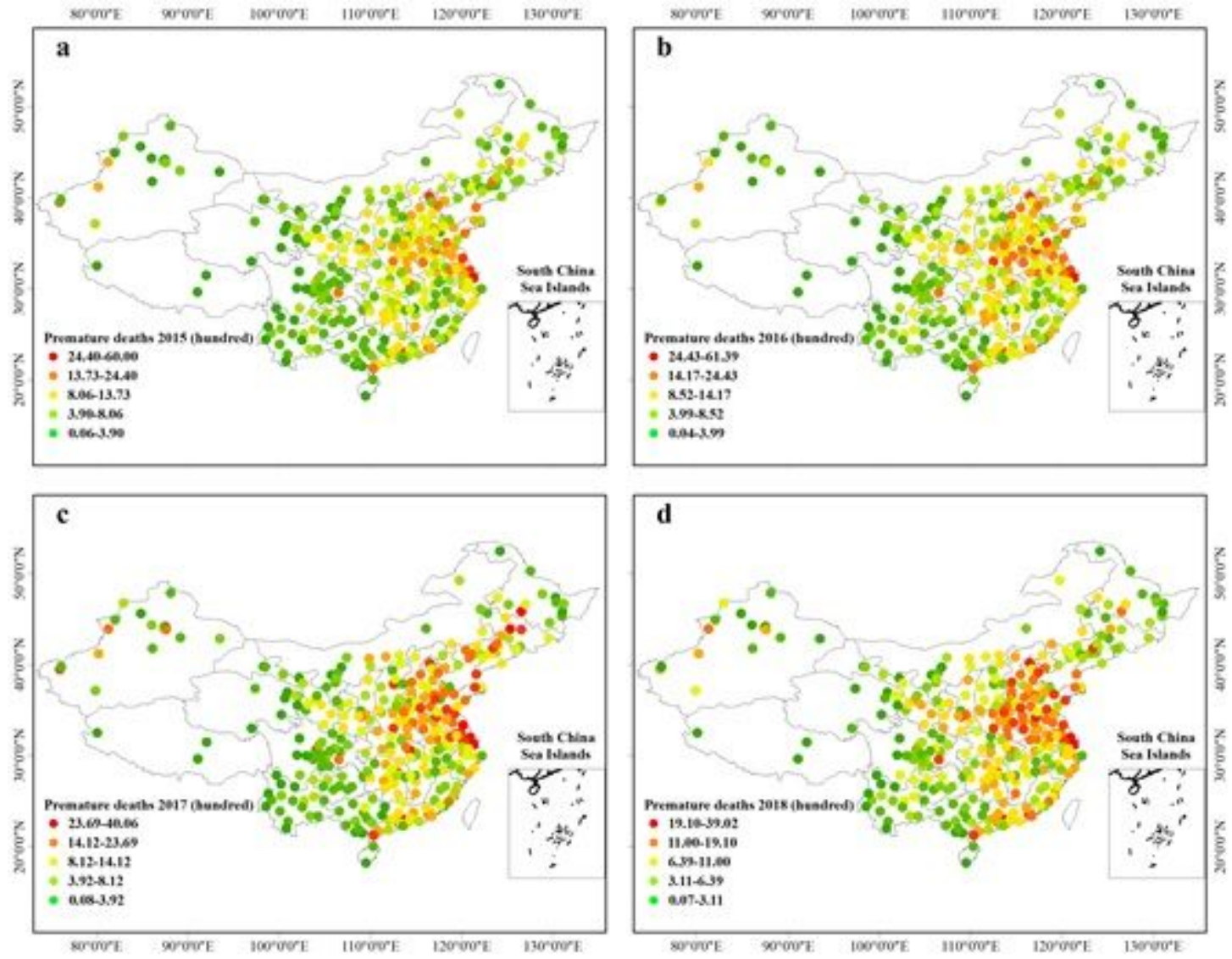

Figure 3

The city-specific 03-realted all-cause mortality in 334 Chinese cities in 2015 (a), 2016 (b), 2017 (c) and 2018 (d). 


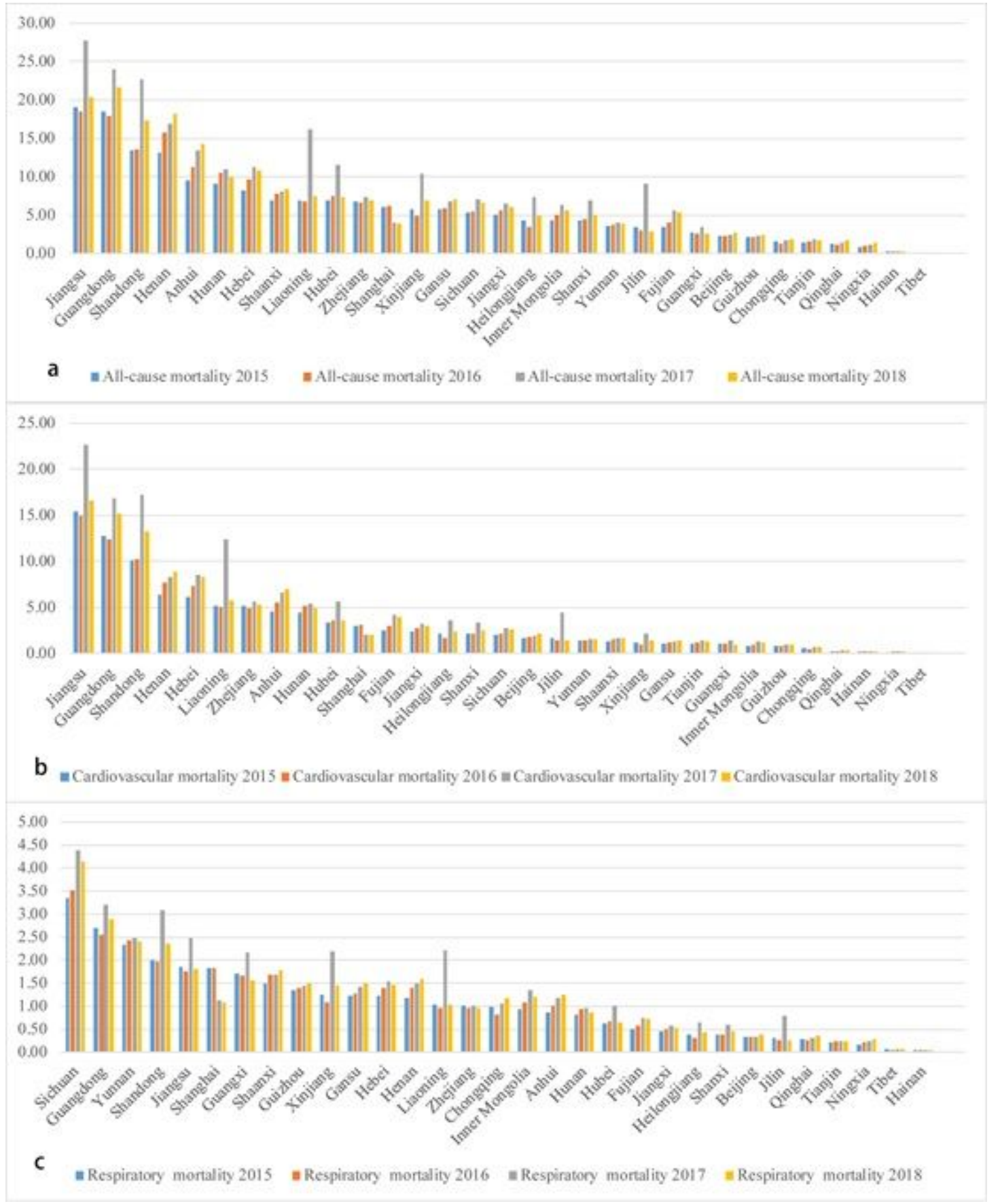

\section{Figure 4}

Provincial-level all-cause (a), cardiovascular (b) and respiratory (c) disease premature death (thousand) due to Ozone short-term exposure during 2015 - 2018. 

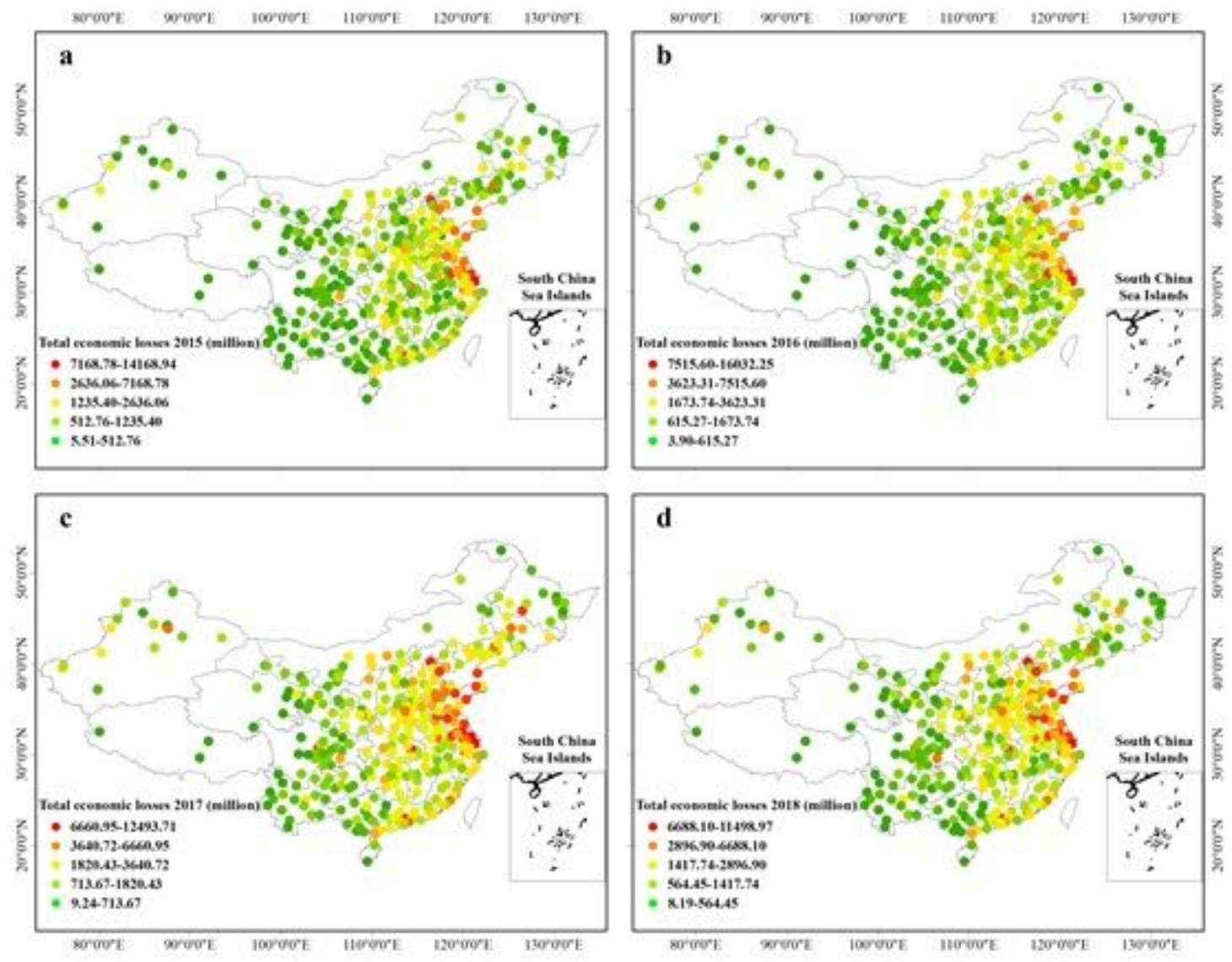

\section{Figure 5}

The city-specific economic losses of 03-related all-cause mortality in 334 Chinese cities in 2015 (a), 2016 (b), 2017 (c) and 2018 (d). 

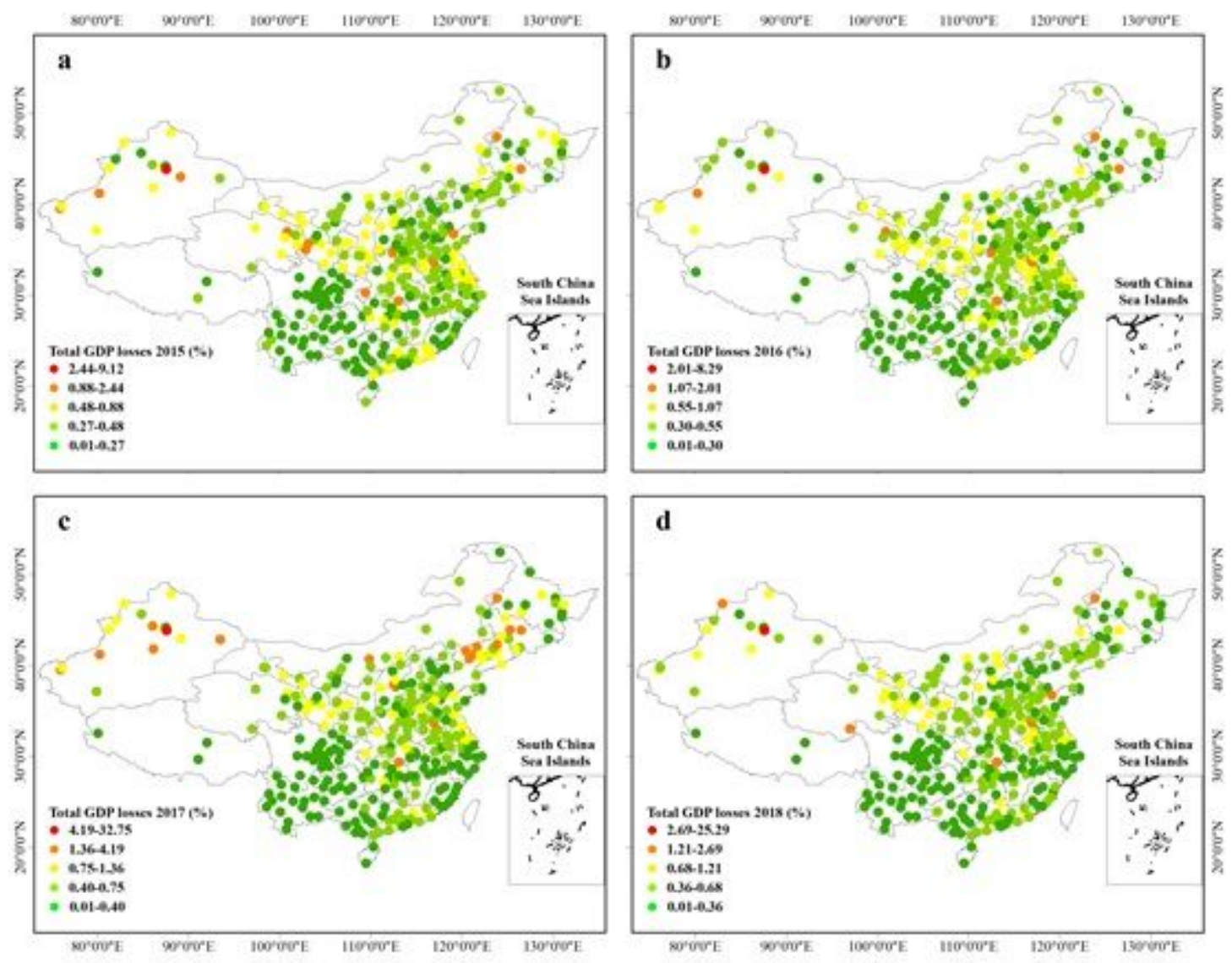

Figure 6

The city-specific GDP impact of 03-related all-cause mortality in 334 Chinese cities in 2015 (a), 2016 (b), 2017 (c) and 2018 (d). 


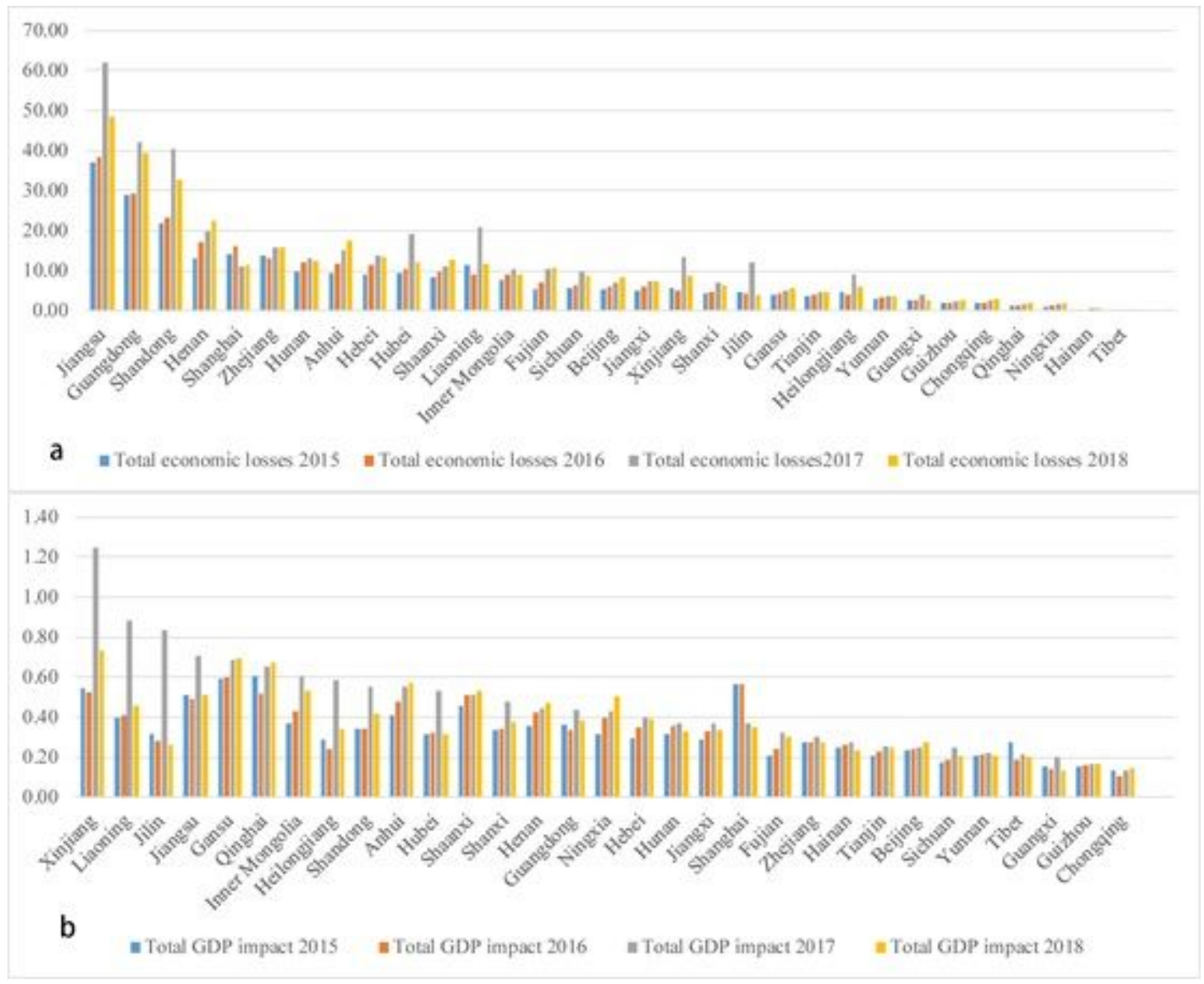

\section{Figure 7}

Provincial-level economic loss (billion) (a) and GDP impact (\%) (b) due to premature death attributable to O3 short-term exposure during $2015-2018$.

\section{Supplementary Files}

This is a list of supplementary files associated with this preprint. Click to download.

- supplement6.docx 